\title{
SEXUALIDADE INFANTO-ADOLESCENTE E SEU RECONHECIMENTO COMO DIREITOS HUMANOS: A NECESSIDADE DE MAIS REFLEXÃO E TEORIZAÇÓES
}

Wanderlino Nogueira Neto*

\section{Resumo}

Este artigo parte do reconhecimento da importância de colóquios científicos para a reflexão sobre os direitos humanos de crianças e adolescentes, criticando a dicotomia entre teoria e prática. Aborda a sexualidade infanto-adolescente no contexto geral da sexualidade humana, situando-a no marco internacional dos direitos humanos, do direito constitucional brasileiro e da sua dogmática vigente. Analisa tal dogmática à luz dos paradigmas ético-políticos e dos princípios jurídicos, submetendo aquela a estes.

Palavras-chave: sexualidade infanto-adolescente; direitos humanos; normativas nacionais e internacionais.

\begin{abstract}
SEXUALITY OF CHILDREN AND ADOLESCENTS AND THEIR RECOGNITION AS HUMAN RIGHTS: THE NEED FOR FURTHER REFLECTION AND THEORIZING

This article recognizes the importance of scientific conferences to discuss the theme of human rights of children and adolescents, criticizing the dichotomy between theory and practice. Discusses sexuality of children and adolescents in the general context of human sexuality, placing it within the framework of international law of human rights and constitutional law in Brazil and its dogmatic force. It analyzes the legal dogmatic paradigms in the light of ethical and political and legal principles, submitting the first to the second one.

Keywords: children and adolescents sexual rights; human rights; national and international legislations.

* Ministério Público da Bahia, Brasil; Seção Brasil da rede Defense for Children International - DCI-DCA-DNI (Associação Nacional dos Centros de Defesa da Criança e do Adolescente-ANCED), através do CEDECA-RIO. E-mail: wnogueiraneto@yahoo.com.br.
\end{abstract}




\section{Por que e para que um colóquio científico?}

Quando se reúnem "intelectuais orgânicos ou autônomos" (no sentido gramsciano) em colóquios científicos, especialmente no espaço da Academia, para discutirem e aclararem conceitos e categorias científicas, logo vêm à baila algumas questôes preliminares, mais das vezes em termos decididamente acríticos: “- Não estaremos teorizando demais, pois o que interessa na verdade é a prática? - Onde estão os operadores das redes de atendimento e por que não se discutem estratégias para fortalecimento das diversas instâncias públicas do sistema de garantia de direitos (SGDH) e para a valorização dos seus profissionais?”.

Os defensores da prevalência da prática (ou ação) alegam que a teoria é inefetiva e descolada da realidade. Por outro lado, muitos daqueles que defendem a prevalência da teoria alegam que os conceitos são as verdadeiras fontes do saber e, portanto, a prática lhes deve ser decorrente, secundária.

Algumas vezes, no movimento de lutas pelos direitos de crianças e adolescentes ${ }^{1}$, esse falso dilema é posto e sustentado. Todavia, a tensão entre reflexão e ação sempre foi presente (não como contradição e sim como tentativa de harmonização) nessa citada história de lutas pelos direitos infanto-adolescentes: teoria e prática buscavam andar de máos dadas, como se pode comprovar analisando-se os fatos históricos recentes. Em texto de avaliação das duas últimas décadas de lutas por direitos infanto-adolescentes no Brasil (Nogueira Neto, 2009a) elencamos três forças que se faziam presentes na construção do novo Direito na área da infância e da adolescência, nas décadas de 1980 e 1990, no Brasil:

(10) "A mobilização dos movimentos sociais e, dentro disso, das expressóes organizativas de movimentos conjunturais e de seus militantes;

(2o) O pensamento acadêmico, explicitado em teorias científicas novas e em estratégias, táticas e metodologias transformadoras;

(30) A nova normativa internacional sobre direitos humanos gerais e especiais/geracionais (Convenção sobre os Direitos da Criança - CDC)”.

Como exemplo desse pensamento acadêmico citado, na composição do primitivo Fórum Nacional das Organizações Não Governamentais de Defesa da Criança e do Adolescente - DCA, na década de 1980, integrava-se uma Rede Nacional dos Núcleos de Estudos e Pesquisas composta por vários núcleos de extensão universitária e organizaçóes não governamentais - ONGs especializadas -, responsáveis por um farto acervo de conhecimentos científicos a respeito da infância e adolescência, em que pese no passado não se ter a mesma proficuidade no campo da reflexão sobre a sexualidade infanto-adolescente como se tem atualmente. 
Impraticável, num bom planejamento, formularem-se políticas, programas/projetos, serviços/atividades e ações públicas se não tivermos levantamentos/ mapeamentos, indicadores, dados, informaçóes, análises e avaliaçóes de boa categoria. E que, nesse trabalho de reflexão/teorização, tentássemos construir consensos mínimos sobre conceitos e categorias ou explicitar dissensos do momento, no campo da sexualidade humana (especificamente da sexualidade infanto-adolescente), dos direitos sexuais e das diversas formas de violências sexuais. Como exemplo disso, temos o Plano Nacional de Enfrentamento da Violência Sexual contra Crianças e Adolescentes (Natal, 1999) que dedicou um dos seus eixos temáticos e estratégicos a Estudos e Pesquisas. Por sua vez, existe rica literatura publicada no Brasil, resultado de estudos e pesquisas, contribuindo para a construção do conhecimento científico e sistematização do saber popular a respeito da temática sexualidade infanto-adolescente, como qualquer bom levantamento do estado-da-arte e de bibliografia especializada a respeito nos ofereça.

Não fossem oportunidades como a do presente Colóquio e outras, difícil seria articularem-se os intelectuais orgânicos que atualmente refletem/atuam nessa área, na forma de fóruns não institucionais de discussão, com metodologia própria para possibilitar a descrição, explicação e projeção dos diversos fenômenos que se explicitam no dia-a-dia da vida de crianças e adolescentes, em torno da sua vivência sexual, das suas necessidades e desejos sexuais e dos seus interesses reconhecidos e garantidos como direitos.

\section{A sexualidade infanto-adolescente e seus conceitos básicos}

Neste esforço conjunto para refletirmos e teorizarmos a respeito do tema posto neste Colóquio Científico, importante se faz aclarar-se a questão terminológica e conceitual surgida com o uso das expressóes violência sexual, abuso sexual, exploração sexual e prostituição infantil.

A primeira expressão (violência sexual), no sentido utilizado hoje pelas políticas públicas, foi construída quando da elaboração do Plano Nacional de Enfretamento da Violência Sexual (Natal, 1999). Nessa oportunidade foi cunhada para designar toda e qualquer forma de violação dos direitos sexuais de crianças e adolescentes, ultrapassando o sentido estrito e tradicional do âmbito do direito positivo brasileiro. É a expressão-gênero mais ampla da qual se desmembram as expressōes-específicas exploração sexual e abuso sexual. O abuso sexual, mais genérico, seria toda intervenção abusiva na sexualidade infanto-adolescente com a 
característica de imposição, de abuso do poder etário, do poder familiar ou do poder de autoridade. Importante, aqui, indagar se esses conceitos e terminologias continuam válidos, tanto para as formulaçóes normativo-jurídicas e político-institucionais, quanto para as definiçóes e conceituaçóes no campo das reflexóes teóricas das diversas ciências (psicologia, sociologia, antropologia, ciência política, criminologia, biologia etc.). A exploração sexual seria toda forma de abuso contra os direitos sexuais de crianças e adolescentes que tenha um caráter comercial, mercantil, isto é, que vise determinado lucro, ganho, vantagem. Repita-se: esses conceitos e terminologias ainda continuam válidos do modo como foram descritos? Por fim, a expressão prostituição infantil seria uma subespécie da exploração sexual. Tecnicamente, no Brasil, se usou e se usa a expressão prostituição quando da violação dos direitos sexuais de pessoas menores de 18 anos, com fins lucrativos, isto é, como forma de exploração da sexualidade para fins de satisfação da lascívia alheia (lenocínio, rufianismo etc.).

Quando da realização, em 1996, do I Congresso Mundial Contra a Exploração Sexual Comercial de Crianças, em Estocolmo (Suécia), promovido pelo UNICEF, definiu-se a prostituição infantil (ali prevista no seu documento-base) como uma das formas da exploração sexual, ao lado da pornografia infantil, do tráfico para fins sexuais e do turismo sexual. A partir daí, deu-se prevalência à expressão mais ampla de exploração sexual, evitando-se, no mais das vezes, o uso da expressão prostituição. Isso tem sentido, politicamente, na formulação de políticas públicas e principalmente no desenvolvimento de estratégias de mobilização social? Cientificamente e jurídico-dogmaticamente, a expressão prostituição infantil terá algo de incorreto?

Pode-se argumentar que a criança ou o adolescente não são realmente prostitutos e sim prostituídos; contudo, de qualquer maneira há prostituição na origem do processo, mesmo sem liberdade - são objetivamente prostituídos e, nesse caso, há objetivamente prostituição. A condição de pessoa em condição peculiar de desenvolvimento (Estatuto da Criança e do Adolescente, 1990) não coloca a criança e o adolescente fora de um processo de prostituição, qualquer que seja sua participação, pois também são sujeitos de direitos e não objetos de tutela. É um tipo peculiar de exploração sexual, sempre intrinsecamente exploratório, sem que se admita a necessidade de comprovação de que se trata de prostituição explorada por outrem, como no caso da prostituição adulta. Em reforço a esse entendimento, é de se lembrar que toda a normativa internacional e toda a legislação nacional vigentes usam a expressão prostituiçâo quando se referem às crianças e aos adolescentes. No Brasil, as organizaçóes da sociedade civil ligadas ao tema viram seus pleitos acolhidos pelo Congresso Nacional e o Estatuto foi alterado 
para se incluir, como seu artigo 244-A, o crime cujo tipo penal é submeter criança e adolescente a exploração sexual ou prostituição. Por sua vez, o Brasil também recentemente ratificou o Protocolo Facultativo à Convençáo sobre os Direitos da Criança que diz respeito à prostituiçâo infantil e outras formas de violaçóes dos direitos sexuais infanto-adolescentes. Nosso país ratificou ainda mais a Convenção 182 da OIT que trata da proibição e eliminação imediata das piores formas de trabalho infantil ${ }^{2}$. E, dentre essas, lá está explicitamente a prostituição infantil.

Por trás de toda a discussão terminológico-conceitual, temos que reconhecer, preliminarmente, que na raiz de tudo que se quiser dizer e fazer sobre o tema da sexualidade infanto-adolescente estão as questóes da dignidade humana, da liberdade e do direito. A partir dessas raízes todas as ciências poderiam trazer seus contributos para o aprofundamento da reflexão (e assim da qualificação da ação) sobre o tema da sexualidade infanto-adolescente e suas diversas formas de violências, abusos, exploraçóes e que outras formas mais se descrevam e se expliquem. Primeiro, é preciso uma concepção de liberdade que a ponha antecedendo ao direito positivado pelo Estado, à lei e às formulaçóes político-institucionais: que a coloque no seio da vida vivida, na conduta humana em intersubjetividade, nas relaçóes interpessoais. E, portanto, uma liberdade que diz muito do seu estar-bem-no-mundo, estar bem consigo e com suas circunstâncias. Uma liberdade que pressupóe o saudável conflito - portanto, a pluralidade e a diversidade. E toda discussão e prática passarão pela questão preliminar da tolerância e respeito com a diversidade e com a liberdade, de cada um. Uma concepção de direito que o ponha igualmente antecedendo à lei emanada do Estado: que o coloque também no seio da vida vivida. E, portanto, um direito que seleciona determinadas situações/relações de conflito, as valoriza e as normatiza, por consequência. Um Direito que é irmão e amigo da Liberdade e não seu antagônico e inimigo. Um Direito emancipador e não meramente regulador. Sendo a sexualidade o ponto fontal da vida humana, o reconhecimento e a garantia da sua liberdade é uma das tarefas magnas do Direito. A regulação emancipatória do exercício dessa liberdade sexual passa a ser a responsabilidade maior do Estado Democrático de Direito (Constituição Federal, 1988), dirimindo conflitos de interesses, possíveis, visando o asseguramento do prazer pessoal do cidadão e da ordem social. A sexualidade humana pressupóe liberdade, diversidade, respeito e tolerância. E a livre expressão dessa sexualidade deve ser reconhecida e garantida como um direito fundamental, indisponível. Quando ameaçados e violados os direitos sexuais de crianças e adolescentes, há que se desenvolverem açóes de proteção jurídico-social em favor desses direitos e outras formas de ação protetiva, como a sócio-jurídico-assistencial, por exemplo, tentando restaurá-los, ressarci-los, em resumo, garantir sua reali- 
zação. Antes disso (não cronologicamente) precisamos de ações que promovam ${ }^{3}$ esses direitos, que facilitem e que favoreçam seu exercício de maneira prazerosa, saudável. Ao mesmo tempo que se falar em proteção/defesa de direitos, há que se falar em promoção de direitos: é preciso enfrentar todas as formas de violência sexual, mas precisamos mais que tudo de açóes afirmativas em favor da sexualidade saudável de crianças e adolescentes. $\mathrm{O}$ melhor mecanismo para a promoção dos direitos à sexualidade saudável e prazerosa de crianças e adolescentes está no desenvolvimento de açóes, atividades, projetos, programas e serviços das diversas políticas públicas.

Desse modo, importante que em primeiro lugar essa questão seja enfrentada por açóes estratégicas da política de direitos humanos (Secretaria de Direitos Humanos da Presidência da República - SDH-PR / Secretaria de Promoção dos Direitos da Criança e do Adolescente - SPDCA-SDH e Conselho Nacional dos Direitos da Criança e do Adolescente - CONANDA), em nível nacional, para garantir o privilegiamento (priorização absoluta), a articulação política e a integração operacional pontual do atendimento a esse público, por todas as políticas públicas, isto é, pelas políticas públicas sociais (educação, saúde, assistência social, previdência, cultura etc.), institucionais (segurança pública, defesa do estado, planejamento/orçamentação etc.), econômicas (cambial, bancária, fiscal etc.) e infraestruturantes (turismo, agricultura, indústria, comércio, transporte etc.). $\mathrm{O}$ enfrentamento da violência sexual é uma questão multidisciplinar, intersetorial, interinstitucional e multiprofissional. Nenhuma política pública deve ter o monopólio sobre esse segmento infanto-adolescente. Por exemplo, os serviços/ atividades e programas/projetos de proteção social da política socioassistencial são importantíssimos nesse enfretamento e no atendimento direto a esses meninos e meninas vítimas de alguma forma de violência sexual. Mas não menos importantes são os serviços e programas de proteção jurídico-social da política de direitos humanos e outros programas e serviços especializados nas políticas de saúde, de educação, de cultura, de turismo, de relaçóes exteriores, de segurança pública e outros mais. É preciso construir e desenvolver intervençóes multiestratégicas sem reducionismos científicos e corporativos.

\section{A intervençáo no campo da sexualidade infanto- adolescente em uma visão holístico-sistêmica}

A partir de uma visão holística e numa ambiência sistêmica, todos os elementos influenciam os demais e são influenciados por tantos outros. Assim, se 
definimos alguns princípios éticos como critérios, eles forçosamente se constituirão como um ponto de equilíbrio operacional e de capacidade de resistência à desagregação de um determinado metassistema, fazendo com que se veja o que for de melhor para todos ou para a maioria da população ou, ao menos, mais especificamente para um determinado segmento da sociedade (infância, adolescência, juventude ou senectude, por exemplo). Em decorrência disso, os pensamentos e as ações contrárias a esses princípios éticos serão eliminados por causa do desequilíbrio que produzem no metassistema resultando em tensóes e conflitos - inefetividade do referido sistema. Os atores sociais que atuam nesse sistema e que incorrem em práticas antiéticas não conseguirão prosperar em um ambiente holístico criado por sistemas crescentemente articulados, integrados, conectados, comunicantes e complementares numa sociedade cada vez mais complexa.

Isso é flagrante quando se pretende desenvolver sistemas operacionais, redes, programas, serviços e açóes no âmbito de políticas públicas. E quando se pretende promover o acesso à justiça no enfrentamento das diversas formas de violência, exploração, discriminação, abusos, crueldade e opressão. A inefetividade, ineficácia e ineficiência dessas açóes e a lacunosidade e a falsidade do pensamento teórico que as justificam e sustentam são logo desmascaradas se analisadas a partir de uma visão sistêmica e holística ${ }^{4}$. Quando colocarmos o desenvolvimento dessas açóes públicas e a formulação do seu discurso justificador sob a perspectiva dos direitos humanos, tudo isso desmoronará desagregadamente, na medida em que se chocar, por exemplo, com os princípios da dignidade humana, da liberdade, da igualdade formal e material, da pluralidade, da diversidade, da universalidade, da não-discriminação, da prevalência do superior interesse da criança etc. A validade desse saber e desse agir ficará, pois, na dependência dessa coerência com os princípios éticos, políticos e jurídicos dos direitos humanos tomados como critérios, como marcos referenciais, para a análise avaliação desse saber e desse agir. As diversas formas de atenção, pelos sistemas de políticas públicas (educação, saúde, assistência social, cultura, segurança pública etc.) e pelo sistema de justiça (varas judiciais, promotorias de justiça, defensorias públicas e outras procuraturas sociais), de questôes como as das crianças e dos adolescentes submetidos a abusos e explorações sexuais - por exemplo - há que serem postas numa ambiência sistêmico-holística, isto é, no seio de uma concertação sistêmica pela promoção e proteção (defesa) dos seus direitos humanos, ou, pelo menos, minimamente, no ambiente de um institucionalizado sistema de garantia de direitos humanos 5 .

Um dos elementos imprescindíveis para uma reflexão e atuação holístico-sistêmica é a multidisciplinaridade (ou inter ou trans). Todavia, a multidisciplinaridade não é um dado preexistente e natural, é mais um construto político. 
Assim, é preciso construí-la. Ela se apresenta como uma opção para articular os saberes científicos e metacientíficos que se ocupam de vários fenômenos e/ou problemas: delinquência, abandono, exploração laboral e sexual, sofrimentos mentais, discriminaçóes, marginalizaçóes, subalternidades, empobrecimento extremo etc. A realidade complexa do mundo de hoje exige uma postura metodológica, por exemplo, diferente, sistêmica, interdisciplinar, sem, contudo, rejeitar pura e simplesmente a abordagem disciplinar tradicional acadêmica. São pressupostos dessa abordagem sistêmica multidisciplinar: 1) a crítica das formas convencionais do conhecimento disciplinar que enfrenta os problemas de forma parcial e segmentada; 2) a incorporação da complexidade dos conhecimentos científicos com os saberes populares tradicionais, metacientíficos; 3) a primazia das indagaçôes de natureza ética e estética.

A crise contemporânea do viver social manifesta-se também como crise do conhecimento, da estratégia epistemológica e da apropriação dos saberes; donde se conclui que ciência e tecnologia, embora forças construtoras, podem se manifestar igualmente como elementos destrutivos do convívio humano. A multidisciplinaridade surge como um processo produtor de novos conhecimentos através do entrelaçamento de diversas disciplinas que procurem redefinir o objeto de conhecimento. Questione-se, pois: - que está em jogo nas estratégias de construção de conhecimentos, de doutrinas, de teses em torno da promoção e proteção dos direitos humanos de crianças e adolescentes (inclusive dos abusados e explorados sexualmente)? Por um lado, verifica-se a apropriação personalista, corporativa e monopolista dos saberes, isto é, dos discursos científicos e metacientíficos justificadores das açóes de garantia desses direitos humanos geracionais e sua valorização social e política como instrumento de construção/ manutençâo e de prestígio e/ou poder. Por outro lado, verifica-se ao mesmo tempo a ocorrência de construção política de discursos científicos articulados e integrados a partir das várias disciplinas que tratam da questâo dos direitos humanos geracionais (filosofia, direito, psicologia, sociologia, ciência política, administração, criminologia, antropologia etc.), a partir das intervençôes e a consideração, como válidos e respeitáveis, dos diversos significados culturais que constituem a condição necessária para a participaçáo dos atores locais, das comunidades, das famílias, das próprias crianças e adolescentes abusados e explorados sexualmente, com seus saberes, culturas e identidades. A complexidade do mundo que nos rodeia exige a participação dos chamados experts, isto é, estudiosos e pesquisadores com reconhecida expertise nas áreas econômica, jurídica, sociológica, antropológica, psicológica, sociológica, histórica, biológica etc., e dos pontos de vista diferentes e complementares que trazem sobre determinado 
problema ou realidade. Isso não representa um simples somatório, mas a recriação e reconstrução dos saberes.

$\mathrm{Na}$ prática da multidisciplinaridade, duas ou mais disciplinas estabelecem intencionalmente conexóes para alcançar um conhecimento mais abrangente e profundo, embora cada disciplina mantenha sua identidade, conserve sua metodologia e observe os limites de sua área. Há um intercâmbio de hipóteses e a elaboração de conclusões que possam induzir uma ação comum e concertada. $\mathrm{Na}$ multidisciplinaridade (menos complexa), tem-se o objeto sendo observado por vários universos disciplinares, determinando três dimensóes de realidade, cada uma com seus respectivos domínios linguísticos, justapostos pelo trabalho de revisão de um coordenadorlarticulador. Como resultados deste modo de produção, ter-se-iam três textos. Neste modo não há cooperação entre as disciplinas, mas há coordenação. $\mathrm{Na}$ interdisciplinaridade (mais complexa), ter-se-ia a mesma situação disciplinar do plano multi, só que agora com uma integração dos respectivos domínios linguísticos de cada disciplina. Esta integração é permitida, facilitada e orientada pela existência de uma temática comum a todas as disciplinas com a qual elas deverão observar o objeto. Como resultado desse modo de produção, continuamos tendo três textos, porém cada um refletindo parte da realidade com o domínio linguístico das outras disciplinas. Este modo exige a cooperação e a coordenação entre as disciplinas. Por exemplo, ter-se-ia um parecer técnico-jurídico, um laudo psicológico e um estudo social. A questão está em como articulá-los e em que nível de complexidade. Isso dependerá do grau de apreensão e domínio que, no caso, tenha o juiz da causa em relação à psicologia, à sociologia, à ciência política. E dos graus de apreensão e domínio que tenham, por sua vez, o psicólogo e o assistente social (no ambiente judicial), por exemplo, em relação à ciência do direito ou à dogmática jurídica, particularmente. $\mathrm{O}$ atendimento à criança e ao adolescente submetidos a processos diversos de violência sexual entre nós, e igualmente sua mais que necessária garantia dos direitos fundamentais, é palco onde esse debate sobre o discurso sistêmico e a interdisciplinaridade (ou mera multidisciplinaridade?) encontra eco, pois a efetividade, eficácia e eficiências das ações públicas decorrentes dependem muito da construção do saber interdisciplinar/multidisciplinar.

A crítica do sujeito interdisciplinar está centrada na ideia de sujeito coleti$v o$, ou seja, do sujeito que emerge como agente nos sistemas operacionais (SUS, SUAS, SNSP, Sistema de Justiça etc.) como integrantes dessa ambiência sistêmica (ou sistema estratégico) de promoção e defesa de direitos humanos de crianças e adolescentes, num sentido mais amplo. Esta visão é considerada idealista, pois baseada no pressuposto do primado explicativo das ideias e de sua autonomia 
frente ao real, dando suficiência absoluta ao sujeito pensante (juiz, gestor público, técnico judiciário, policial, advogado etc.) sobre os objetos (conflito com a lei, direitos humanos, violência etc.). A interdisciplinaridade deve ser vista como construto ideológico da filosofia do sujeito e nada mais é do que uma filha do capitalismo (Nogueira Neto, 2008). Desse modo, por exemplo, importante que, na construção de fluxos operacionais ou na definição de procedimentos judiciais e administrativos, a centralidade esteja não tanto nos atores sociais e seus agentes responsáveis pelo agir do Estado (Judiciário, Policia, Ministério Público, Escola etc.) e sim na própria criança ou adolescente abusado ou explorado sexualmente. Assim sendo, o conflito de ideias, na ambiência sistêmico-holistica (sistema estratégico de garantia de direitos humanos, por exemplo), é salutar e construtor do saber interdisciplinar, sem dominações do conjunturalmente saber hegemônico (a Ciência do Direito? A Psicologia? A Sociologia? A Antropologia? A Ciência Política?) sobre os demais, num falso consenso imposto, que escamoteia legítimos dissensos. Por sua vez, outro elemento constitutivo no processo de construção de uma ambiência sistêmico-holística é a intersetorialidade, na qual precisamos pôr nossa lupa e refletir sobre seu papel no atendimento a crianças e adolescentes abusados e explorados sexualmente.

A intersetorialidade é uma prática social que vem sendo construída com base na existência de profundas insatisfaçóes, principalmente no que se refere à capacidade das organizaçôes em dar resposta às demandas sociais e aos problemas complexos vivenciados pelos cidadãos. A crítica à fragmentação (produzida pela racionalidade cientificista, predominante na maneira de pensar e organizar o mundo) existe há muito tempo e resiste hoje ainda. No entanto, as evidências de esgotamento desse paradigma têm sido cada vez maiores. Essa crítica atualmente produz mais eco e tem maior capacidade de estimular alternativa porque o mundo foi-se tornando mais complexo, produzindo problemas e situaçóes novos que o conhecimento especializado e fragmentado náo tem capacidade para explicar, nem a ação setorial tem capacidade de resolver. $\mathrm{O}$ conceito de intersetorialidade toma como base a ideia de interdisciplinaridade. São termos correlatos.

Multissetorialidade: é um sistema que funciona através da justaposição de instâncias públicas (e seus agentes) em um único nível, estando ausente uma cooperação sistemática entre os diversos campos do agir.

Intersetorialidade: a noção de intersetorialidade implica uma axiomática comum a um grupo de instâncias públicas conexas (intrassistemas ou intersistemas operacionais, como o SUAS, SUS, Sistema de Justiça, Sistema de Segurança Pública etc.), cujas relações são definidas a partir de um determinado nível de 
cooperação ocupado por uma dessas instâncias; esta última, geralmente determinada por referência à sua proximidade a uma temática unificada, mas que atua não somente como integradora e mediadora da circulação das diversas atuaçóes, mas principalmente como coordenadora desse campo operativo.

Transetorialidade: indica a integração de açóes de diversas instâncias públicas de um campo particular sobre a base de uma axiomática compartilhada e implica a criação de um campo novo que idealmente seria capaz de desenvolver uma autonomia teórica e metodológica.

No que se refere à aplicação da ideia de intersetorialidade nas políticas públicas, a lógica intersetorial pode ser mais permeável à participação do cidadão, já que suas necessidades se apresentam como no mundo real, intrinsecamente interligadas, contribuindo para a reformulação da relação entre Estado e Sociedade. Mais especificamente, a lógica intersetorial pode ser mais permeável à participação nos processos, amplamente, de crianças e adolescentes abusados e explorados sexualmente, dos próprios agressores (como estamos longe disso!), das famílias, da comunidade próxima ${ }^{6}$ e outros atores envolvidos. Através do paradigma da intersetorialidade, pode-se ter uma visão completa dos fluxos e procedimentos que ocorrem no atendimento público ao adolescente em conflito com a lei (com a garantia dos seus direitos e a sua responsabilização jurídica especial) e das suas conexóes entre os vários e diferentes níveis do contexto. A contribuição do paradigma da intersetorialidade é valiosa na solução de problemas que parecem insolúveis, existentes no mundo das pessoas e instituiçóes (SUS, SUAS, p. ex.).

Como dito antes, uma perspectiva de trabalho intersetorial envolve mais do que justapor ou compor projetos e açóes que continuem sendo formulados e realizados setorialmente. $\mathrm{O}$ conceito possui uma perspectiva muito maior e tem um conjunto de implicações para a ação do Estado através do Sistema Justiça e dos Sistemas (únicos ou unificados) das Políticas Públicas. A criança e o adolescente abusado ou explorado sexualmente, no atendimento público garantindo seus direitos (educação, saúde, assistência social, cultura, segurança pública, trabalho, habitação etc.) e na atuação do Sistema de Justiça, necessitam que seus problemas sejam tratados como eles se apresentam na realidade, ou seja, na sua totalidade e não de forma fragmentada.

$\mathrm{O}$ tratamento das demandas e dos problemas vivenciados por crianças e adolescentes em situação de violência sexual demanda uma visão integrada dos vários aspectos/processos que constituem a vida deles (saúde, emprego, educação, habitação, etc.). Por exemplo, ter saúde deve ser complementado com uma educação de qualidade, possibilidade de inserção no mercado de trabalho, etc. 
Percebe-se entáo que o conceito de intersetorialidade está relacionado com as noçôes de conhecimento (disciplinaridade) e poder profissional. A questão do conhecimento, enquanto disciplinaridade e multidisciplinaridade, já se discutiu atrás: ele forma um conjunto de interpretaçôes do mundo e das atividades humanas com alguns elementos prescritivos em relação ao modo de abordar a solução do problema. E é possível negociar essa questão entre os profissionais e seus setores (a partir de uma visão crítica desse conhecimento disciplinar a se fazer interdisciplinar ou, pelo menos, multidisciplinar), pois ela é explicitamente baseada em teorias científicas que precisam ser formuladas, divulgadas e discutidas no diálogo. E, além do mais, sujeitas à aceitação ou críticas, formando, desse modo, base para avanços científicos, como demonstrado anteriormente.

Já o poder profissional reside na capacidade politica de usar o conhecimento. A relação estabelecida entre diferentes profissionais de um mesmo setor, ou de diferentes setores, pode significar a formação dessa necessária ambiência sistêmica (e, em certos casos, de redes) e, desse modo, auxiliar no esforço de uma abordagem intersetorial na questão do atendimento ao público indicado. Ou seja, o esforço de se estabelecerem processos de políticas públicas intersetoriais, procedimentos de acesso à justiça intersetoriais e estratégias de controle social e institucional, tudo isso tem que lidar com tensóes decorrentes das maneiras pelas quais os operadores/agentes de diferentes setores (ou sistemas operacionais, como o Sistema Justiça, o SUS, o SUAS, o SENASP etc.), ou pelas quais os atores/operadores, com diferentes visóes sobre um mesmo problema dentro de um mesmo setor, se relacionam entre si. Os profissionais exercem fortíssima influência no processo de definição dos problemas, na produção e discriminação de conhecimento e na interpretação e implementação do seu agir próprio, setorial. Ou seja, um processo intersetorial deve ter não só o esforço de trabalhar de modo integrado diferentes conhecimentos, algo por si só difícil, mas também levar em conta como se dá o relacionamento entre profissionais de diferentes formaçóes. Baseando-nos numa abordagem intersetorial, percebe-se que os problemas da sociedade devem ser considerados como um conjunto único, da maneira como eles se apresentam no cotidiano da sociedade, e que devem ser tratados na sua totalidade. No entanto, vê-se que eles se apresentam de um modo que o Estado ou qualquer outra organização sozinha e com conhecimentos especializados e fragmentados não conseguiriam solucioná-los em virtude da complexidade de como eles são percebidos na sociedade. $\mathrm{O}$ uso da intersetorialidade pode implicar na utilização do conceito de rede. Neste ponto, esse conceito pode ser útil, já que ele pretende vincular os vários atores em torno de diferentes aspectos de um problema em um determinado segmento da sociedade. Mas essa discussão sobre redes já extrapola o campo 
da nossa discussão sobre ambiência sistêmica, sobre sistema estratégico de garantia de direitos, que inclui não só a promoção de direitos humanos no âmbito dos sistemas operativos das políticas públicas (onde se constrói a rede), mas também a defesa desses direitos humanos através do acesso à justiça.

A promoção de direitos na esfera das políticas públicas poderá contar na sua operacionalização do agir dos seus setores próprios com a possibilidade de alguns deles atuarem em rede (nem todos, pois o conceito de rede é de gestão pública e é mais restrito que o uso ampliado feito pelo senso comum). A guetificação do saber e da prática, nesse campo da promoçáo e defesa/proteção de direitos humanos (através das políticas públicas e do acesso à justiça) e os conflitos decorrentes, que se criam entre as categorias profissionais envolvidas (magistrados, promotores, policiais, psicólogos, trabalhadores sociais, médicos, gestores, pedagogos etc.), são grandes empecilhos a serem vencidos com a construção consensuada de um saber multidisciplinar e de uma prática intersetorial. Ao juiz, ao advogado e ao promotor, por exemplo, se exige que não sejam meramente técnico-jurídicos, operadores do direito, positivistas dogmáticos, mas que componham esse seu saber e agir com os das demais ciências e artes, como a Filosofia, a História, a Sociologia, a Psicologia, a Pedagogia etc. Por outro lado, ao psicólogo, ao assistente social, ao médico e outros profissionais, por exemplo, que não sejam só especialistas numa determinada normalização técnica e senhores de uma política de porteira fechada, mas componham eles o seu saber e agir com as demais ciências e os demais especialistas de outras áreas do conhecimento. Finalmente, importante é que ambos os lados não reconheçam o Direito apenas como moldura, uma restrição e limitação aos demais campos e não (como deveria ser) parte integrante da paisagem. Mas a ideia é que todos os atores sociais e seus agentes/operadores - sem distinção do seu modo de agir e do seu papel específico no Estado e na sociedade civil organizada - podem criar um ambiente sinérgico e sistêmico para dar conta da questão maior hoje, no mundo (ao lado da democratização e do desenvolvimento equilibrado autossustentável), que é de garantir a prevalência dos direitos humanos (Constituição Federal, 1988).

\section{Dogmática jurídica nacional e internacional: breve levantamento e explicitaçáo dos marcos normativos}

Não está em nossa proposta de trabalho neste texto analisar mais profundamente a dogmática jurídica vigente no Brasil, isto é, o ordenamento jurídico 
positivo a respeito da questão da garantia dos direitos sexuais de crianças e adolescentes e do enfrentamento legal das diversas formas de violência sexual (Estatuto - art. 87, V). Nossa proposta é tratar do tema no campo da Ciência do Direito (Teoria Geral do Direito), da Filosofia do Direito e da Sociologia Jurídica. Pretende-se fazer de maneira mais ampla essa reflexão, de caráter preliminar ao estudo da dogmática jurídica a ser feito adiante em outro momento: análise dos valores paradigmáticos ético-políticos e dos Princípios Gerais do Direito que nos sirvam para o trabalho de exegese desse direito positivo vigente e de construção de nova ordem jurídica e político-institucional (de lege ferenda), caso necessário.

Essa reflexão, acima apresentada, sobre os aspectos ético-políticos e jurídicos poderá servir para a análise e avaliação dos seguintes instrumentos normativos, à luz desses paradigmas e princípios, numa visão sistêmico-holística, isto é, multidisciplinar, intersetorial e multiprofissional, como se verá adiante: 1) Constituição Federal Brasileira; 2) Convenção sobre os Direitos da Criança (1989/1990); 3) Protocolo Facultativo sobre venda de crianças, prostituiçâoo infantil e pornografia infantil; 4) Estatuto da Criança e do Adolescente (1990); 5) Convenção contra o Crime Organizado Transnacional e seu Protocolo Adicional sobre Prevençáo e Punição do Tráfico de Pessoas - Convenção de Palermo (2000/2004); 6) Leis Orgânicas das Políticas Públicas (LOS, LDB, LOAS etc.); 7) Leis Orgânicas de Instituições do Sistema de Justiça (LOMAN, LONMP, LONDP etc.); 8) Demais instrumentos normativos nacionais (leis complementares e leis ordinárias, decretos, resoluções colegiadas, instruçóes normativas, normas operacionais básicas, portarias etc.).

Com a Convenção das Nações Unidas sobre os Direitos da Criança, em nível internacional, e com a Constituição Federal de 1988 e o Estatuto da Criança e do Adolescente em 1990, no Brasil, a criança e o adolescente tiveram explicitada sua condição simultaneamente de "sujeito de direitos e de pessoa em processo de desenvolvimento" (Estatuto da Criança e do Adolescente, art. 15). Isto é, cidadãos livres, mas com o exercício dessas liberdades condicionado a certos fatores e condiçóes, isto é, com sua capacidade do exercício de quaisquer dos seus direitos limitados estritamente pela lei. Assim, a chamada proteção integral a esse direito, à afetividade e sexualidade, deve ser considerada, por inferência natural, como uma proteção do seu desenvolvimento físico, mental, moral, espiritual e social, em condiçôes de liberdade e de dignidade (Estatuto da Criança e do Adolescente, art. $3^{\circ}$ ). Um direito subjetivo, decorrente do seu direito à convivência familiar e comunitária, como previsto no Estatuto (Capítulo III). Mas, considerando-se que a liberdade afetivo-se- 
xual da criança e do adolescente tem o seu exercício limitado pelo seu grau de desenvolvimento bio-psico-social, há que se colocar, mesmo assim, essa liberdade afetivo-sexual como um direito e regulá-la de maneira emancipatória e não castradora. A normatização jurídica virá para garantir a plenitude do direito à afetividade e à sexualidade, numa construção só aparentemente contraditória: limita-se o exercício do direito para garantir a plenitude do direito. Assim sendo, em primeiro lugar, é de se aplicar o princípio constitucional a respeito dos direitos fundamentais do cidadão: tudo é permitido, exceto o que a lei vedar expressamente. $\mathrm{E}$ a criança $\mathrm{e} \mathrm{o}$ adolescente, para efeito de garantia dos seus direitos fundamentais, deixam de ser cidadáos? Nunca! A leitura do art. 227 da Constituição Federal assegura que o rol de direitos ali enunciados não exclui os direitos humanos previstos na parte geral da Constituição, quanto aos cidadãos em geral.

Para se assegurar a liberdade de consentir de qualquer criança ou adolescente (inclusive no campo das variadas expressóes possíveis de sua sexualidade ${ }^{7}$ ), o Estado e o Direito devem proteger esses cidadãos dos vícios de consentimentos, isto é, das formas violentas, fraudulentas, enganosas, indutoras e exploratórias de consecução do seu consentimento por outrem. As expressóes diversificadas da sexualidade da criança e do adolescente só podem ter limites na norma jurídica. E nunca limitadas pelo arbítrio do magistrado e do gestor público ou pelos nossos preconceitos morais e sociais. A intervenção estatal nesse campo da afetividade/sexualidade só será legítima - ética e socialmente - para garantia do direito correspondente, para sua proteção de relação a abusos contra o direito e para a responsabilização dos violadores/abusadores. Garantia da sua liberdade e da sua dignidade, da sua vida e da sua saúde: nunca dos costumes públicos, como estúpida e anacronicamente prevê a legislação penal (em reforma!), contrariando os novos paradigmas constitucionais que garantem a igualdade de direitos de mulheres, crianças e adolescentes - as maiores vítimas dessa visão machista, adultocêntrica e conservadora do pensamento jurídico-penal brasileiro, já nos seus estertores. Em concreto, o direito positivo brasileiro tem ainda suas definiçóes a serem urgentemente revistas (apesar da profunda revisão pela qual passou depois da CPMI do Congresso Nacional), à luz dos novos (!) princípios constitucionais e da realidade social brasileira, pela via legislativa ou mesmo pela via pretoriana. Desta maneira, de lege data, há que se considerar violaçâo de direito todo o ato sexual praticado com crianças e adolescentes com menos de 14 anos: até aí, em termos absolutos, presumir-se-á a violência contra tal criança ou adolescente. E ter-se-á o estupro e o atentado violento ao pudor, por exemplo, nos termos do Código Penal brasileiro, com mais rigor punitivo para o primeiro ${ }^{8}$. 
Qualquer expressão de sexualidade (no sentido estrito) é vedada ao menor de 14 anos, pelo mesmo Código Penal. Mas a afetividade-sexualidade ampla, intrínseca e natural dessa geraçấo permanece em estado de latência e se manifestando peculiarmente de maneiras várias e possíveis (masturbação, jogos lúdico-sexuais, por exemplo). Entre 14 e 18 anos, segundo o Código citado, não se presume violência: há que se provar em concreto, caso a caso. E nessa hipótese, comprovada a violência real, o Estado e o Direito protegem a liberdade sexual do adolescente com relação ao seu agente violentador. Mas procura-se igualmente proteger esse adolescente, nessa faixa geracional, de outras formas de desrespeito à sua liberdade afetivo-sexual e a sua dignidade humana: fraudes, enganos, induzimentos, explorações etc. E ter-se-á o lenocínio, o assédio sexual, a promoção da exploração sexual etc., também nos termos do Código Penal e do Estatuto da Criança e do Adolescente, com formas ainda ético-socialmente legítimas de regulação da sexualidade dessa faixa geracional e outras francamente ultrapassadas por sua vagueza e possibilidade do arbítrio policial-judicial. Acima dos 18 anos, não se trata mais de adolescente protegido pela lei e sim de um adulto, com capacidade de exercício pleno da sua afetividade-sexualidade.

\section{Indicativos para análise/avaliaçáo crítica da dogmática jurídica (Direito Positivo) Brasileira}

$\mathrm{Na}$ aplicação de todas e quaisquer normas da dogmática jurídica nacional e internacional sobre o abuso e a exploração sexual de crianças e adolescentes, dê-se prevalência aos Valores paradigmáticos ético-políticos dos direitos humanos: dignidade humana, liberdade, equidade e diversidade identitária, por exemplo. $\mathrm{Na}$ interpretação de todas essas normas jurídicas citadas, os Valores devem servir de chave exegética. Por sua vez, na aplicação mais especificamente das normas da dogmática jurídica de ordem infraconstitucional, dê-se prevalência aos princípios jurídicos dos direitos fundamentais (direitos humanos positivados), com base na hierarquia das normas jurídicas: (a) prevalência das normas constitucionais e das normas infraconstitucionais; e (b) prevalência das normas-principios sobre as normas-regras.

A partir daí, à guisa de conclusóes e de indicaçóes, apresenta-se aqui para aprofundamento e debate:

1. Defenda-se e se dê efetividade ao princípio constitucional da aplicabilidade direta e imediata dos princípios constitucionais no campo 14,1 
2. Quais as consequências práticas - em termos de exegese jurídica e, portanto, de alteração da formulação de políticas públicas (programas, serviços e açóes) - da recente alteração legislativa no objeto material da tutela jurídico-penal: isto é, de crimes contra os costumes para crimes contra a liberdade e dignidade humana?

3. O depoimento judicial especial de crianças, como posto na normativa internacional e nacional, de lege data e de lege ferenda (exemplo, o chamado depoimento sem dano de projeto de lei em tramitação): há um aparente conflito entre as normas jurídicas principiológicas jurídicas da titularidade de direitos e a do superior interesse, entre essas e as normas referentes ao direito à proteção especial e ao direito à participação.

4. Qual o foco prioritário e prevalente: o foco no combate ao crime organizado ou na proteçáo especial aos direitos da vítima? Prevalência do Protocolo Adicional à Convenção de Palermo ou do Protocolo Facultativo da Convenção sobre os Direitos da Criança, em caso de aparente conflito? Complementaridade e prevalência do segundo instrumento normativo por se tratar de instrumento explicitador e garantidor de direitos humanos?

\section{Referências}

Brasil. Estatuto da Criança e do Adolescente. Lei Federal n. 8.069, de 13 de junho de 1990. Inojosa, R. M. (2001). Sinergia em políticas e serviços públicos: desenvolvimento social com intersetorialidade. Cadernos FUNDAP, 22, 102-110.

Nogueira Neto, W. (2008). Direitos humanos de geração. Fortaleza: SEDH-PR \& CEDCA-CE. Nogueira Neto, W. (2009a). Avaliando os 20 anos de lutas por direitos da criança e do adolescente no Brasil. Recife: UNICEF.

Nogueira Neto, W. (2009b). Sistema de garantia dos Direitos Humanos de crianças e adolescentes. Sáo Paulo: ABMP.

Nogueira Neto, W. (2011). Matriz interinstitucional do enfretamento da exploração sexual. Marcos conceituais e normativos. Organização Lúcia Leal e Fátima Leal. Brasília: VIOLES - Universidade Nacional de Brasília - UnB.

ONU. (1989). Convenção sobre os Direitos da Criança. Genebra: ONU.

Ratner, H. (2006). Pensamento sistêmico e desenvolvimento auto-sustentável. Revista Espaço Acadêmico, 56, 1-15.

Thiry-Cherques, H. R. (julho-agosto/2009). Max Weber: o processo de racionalização e o desencantamento do trabalho nas organizaçóes contemporâneas. Revista de Administração Pública, 897-918. 


\section{Notas}

${ }^{1}$ Movimento conjuntural, todavia vinculado muitas vezes a movimentos sociais estruturantes.

${ }^{2}$ A Convençáo 182-OIT não determinou que só se fossem erradicar essas piores formas de trabalho infantil. A Convenção 138, mais genérica, trata da erradicação gradual de toda forma de trabalho infantil. A 182 estrategicamente elege algumas formas mais danosas de trabalho (não piores, como na tradução para o português) para um processo de proibição e eliminação imediatas, como formas de erradicação do trabalho mais urgente, emergencial, rigorosa, não gradual.

${ }^{3}$ Promoção de direitos, aqui em sentido diverso da promoção no campo da saúde, da assistência social, por exemplo.

${ }^{4}$ Expressão "Sistema”, aqui usada num sentido mais amplo e radical que o sentido que se atribui com precisão ao de "Rede" (de atendimento direto).

${ }^{5}$ Como o metassistema institucionalizado no Brasil pela Resoluçáo 113 - CONANDA, com base na Convenção sobre os Direitos da Criança e por inferência a partir do Estatuto da Criança e do Adolescente.

${ }^{6}$ Bairro, vizinhança, grupamento étnico ou de base geográfica restrita, quilombos, aldeias, favelas, acampamentos etc.

${ }^{7}$ É preciso cuidar para não se restringir a ampla sexualidade à estrita genitalidade.

${ }^{8}$ Típico culto himenólatra, com ranço machista e patrimonialista.

Recebido em 03 de outubro de 2011 Aceito para publicaçáo em 25 de março de 2012 